This is the author's final, peer-reviewed manuscript as accepted for publication. The publisher-formatted version may be available through the publisher's web site or your institution's library.

\title{
Thermally assisted high efficiency ductile machining of nanocrystalline hydroxyapatite: a numerical study
}

Jianfeng Ma, Nathan Pelate and Shuting Lei

\section{How to cite this manuscript}

If you make reference to this version of the manuscript, use the following information:

Ma, J., Pelate, N., \& Lei, S. (2013). Thermally assisted high efficiency ductile machining of nanocrystalline hydroxyapatite: A numerical study. Retrieved from http://krex.ksu.edu

\section{Published Version Information}

Citation: Ma, J., Pelate, N., \& Lei, S. (2013). Thermally assisted high efficiency ductile machining of nanocrystalline hydroxyapatite: A numerical study. Ceramics International, 39(8), 9377-9384.

Copyright: (c) 2013 Elsevier Ltd and Techna Group S.r.l.

Digital Object Identifier (DOI): doi:10.1016/j.ceramint.2013.05.054

Publisher's Link: http://www.sciencedirect.com/science/article/pii/S0272884213005683

This item was retrieved from the K-State Research Exchange (K-REx), the institutional repository of Kansas State University. K-REx is available at http://krex.ksu.edu 


\title{
Thermally Assisted High Efficiency Ductile Machining of Nanocrystalline Hydroxyapatite: A Numerical Study
}

\author{
Jianfeng $\mathrm{Ma}^{1}$, Nathan Pelate ${ }^{1}$ and Shuting $\mathrm{Lei}^{\mathrm{i}^{*}}$ \\ ${ }^{1}$ Department of Aerospace \& Mechanical Engineering, Saint Louis University, Saint Louis, MO \\ 63103,USA \\ ${ }^{2}$ Department of Industrial \& Manufacturing Systems Engineering, Kansas State University, \\ Manhattan, KS 66506, USA
}

\begin{abstract}
This study investigates the role of thermal assistance and tool geometry on ductile regime machining of a nanocrystalline (nano-HAP) bioceramic using numerical simulation. AdvantEdge FEM Version 5.9 is used to conduct the simulation of orthogonal machining of the nano-HAP material. Thermal boundary conditions are specified to approximate laser preheating of the work material. The effects of operating conditions (preheat temperature, rake angle, and edge radius) on critical depth of cut, cutting force, and thrust force are investigated. Based on the pressurebased criterion for ductile regime machining (DRM), the dependence of critical depth of cut on preheating temperature is examined. It is found that for different combinations of rake angle and edge radius, the critical depth of cut increases as thermal boundary temperature increases. In addition, it is concluded that using higher thermal boundary temperature for smaller negative or $0^{\circ}$ rake angle, we can achieve the comparable critical depth of cut obtained by using a higher negative rake angle, which usually generates higher thrust force and consequently deteriorates the dimensional accuracy of finished parts.
\end{abstract}

KEY WORDS: thermally assisted machining, ductile machining, hydroxyapatite, FEM simulation

* Corresponding author. Tel.:+1 785-532-3731

E-mail address: lei@ksu.edu 


\section{INTRODUCTION}

Pioneer Surgical Technology (PST) developed a nanocrystalline hydroxyapatite bioceramic for orthopedic applications and has overcome the traditional limitations of conventional calcium phosphates via its proprietary nanostructured biomaterials processing technology. The resulting calcium phosphate nanocrystals possess unique thermal, chemical and physical properties, as well as high bioactivity in in vitro and in vivo testing. They can be consolidated into large, mechanically robust nanocrystalline hydroxyapatite (nano-HAP), which is highly suitable for orthopedic applications[1-3].

Grinding has been attempted for making orthopedic devices from fully dense nanocrystalline monoliths, but grinding produces surface and subsurface damages that reduce the strength of the inter-vertebral devices in field use. PST found that grinding can result in reduction in strength normally $48 \%$ because of the grinding induced microcracks. A post-process such as polishing, glazing, and annealing can restore much of the lost strength; however, a postprocess adds additional costs and processing steps on top of grinding. Therefore, there is a definite need to develop a cost-effective single-step machining process for this newly developed bioceramic nano-HAP that can minimize the surface and subsurface damages, therefore minimizing loss of material strength, for this newly developed bioceramic nano-HAP.

Recent research on machining of brittle materials reveals that the ductile behavior of brittle materials is pressure-induced, with the brittle-to-ductile transition happening when the hydrostatic pressure during loading reaches the hardness value of these materials [4]. Ductile regime machining of ceramics can be achieved at low depths of cut (below the critical depth of cut) under certain controlled conditions [5,6]. Alternatively, thermal softening is another possible mechanism for ductile behavior, which is the purpose of laser assisted machining. The advantage

* Corresponding author. Tel.:+1 785-532-3731

E-mail address: lei@ksu.edu 
of ductile regime machining over brittle machining is that ductile regime machining can minimize surface and subsurface damage with a surface roughness on the order of a few nanometers. For each brittle material, the critical depth of cut for ductile regime machining is different. In this research, a numerical method is used to model and simulate the two dimensional (2D) laser assisted machining process of the newly developed nano-HAP and to gain insight of the cutting conditions (critical depth of cut) under which ductile regime machining of this material can be achieved. This research aims to accelerate the application of the nano-HAP as orthopedic implants by providing a high performance machining technology.

\section{2D FEM SIMULATIONError! Reference source not found.}

Figure 1 shows the FEM laser assisted orthogonal machining model. Laser assisted machining (LAM) uses a laser to heat the workpiece to make it soft so that it can be efficiently removed by a cutting tool. In this FEM model, laser heating is approximated with a constant temperature applied to the top surface of the workpiece based on laser heating conditions. The convection and radiation boundary conditions are neglected in this study. The initial temperature of the workpiece is set at room temperature. The length of the workpiece is $2 \mathrm{~mm}$ and the height of the workpiece is $0.8 \mathrm{~mm}$. This model utilizes the updated Lagrangian finite element formulation in conjunction with continuous meshing and adaptive meshing techniques. The convergence tests have been done to get the reliable numerical results. Standard mode is used in all simulations. The bottom edge of the workpiece is fixed in the y direction and the top and back surfaces of the tool are fixed in all directions. The maximum element size is set as $0.02 \mathrm{~mm}$ and the minimum element size is set as $0.004 \mathrm{~mm}$. A mesh refinement factor of 4 is used and a mesh

\footnotetext{
* Corresponding author. Tel.:+1 785-532-3731
}

E-mail address: lei@ksu.edu 
coarsening factor of 4 is utilized. The relative motion between the workpiece and the cutting tool is realized by the horizontal movement of the workpiece at the specified cutting speed.

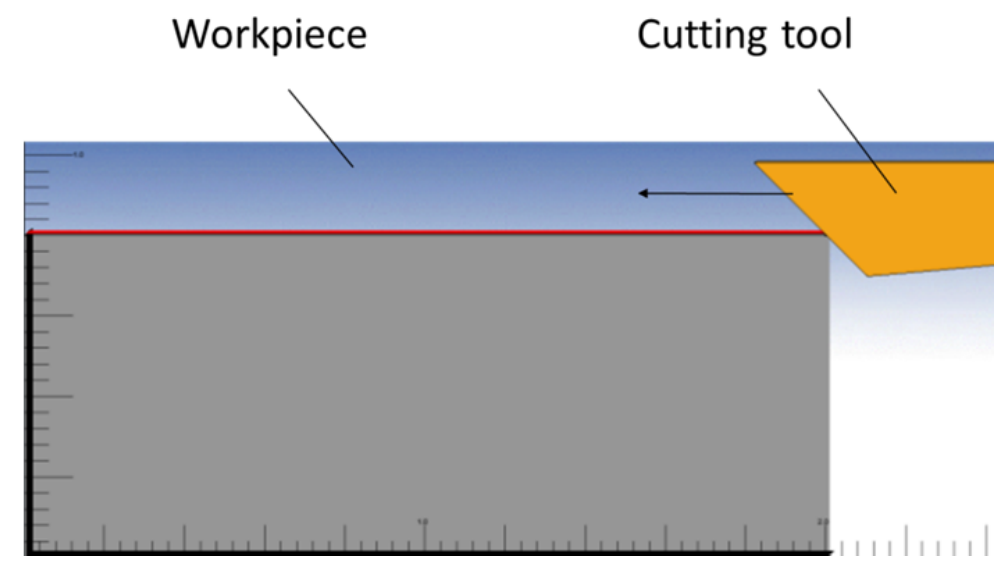

Figure 1. AdvantEdge tool/workpiece diagram

The workpiece is the newly developed nanocrystalline bioceramic material called nanoHAP (nanohydroxyapatite). Relatively speaking, it is soft compared to most ceramics, having a hardness of $0.5 \mathrm{GPa}$. The material parameters are shown below in Table 1. In addition, the thermal properties are given in Table 2. These properties are obtained from literature and Pioneer Surgical Technology Inc. [6-10].

Table 1: Workpiece (nano-HAP) Material Parameters

\begin{tabular}{|c|c|c|}
\hline $\begin{array}{c}\text { Workpiece material } \\
\text { parameters }\end{array}$ & Magnitude & Unit \\
\hline Initial yield stress & $3.125 \times 10^{8}$ & $\mathrm{~Pa}$ \\
\hline Density & 2300 & $\mathrm{~kg} / \mathrm{m}^{3}$ \\
\hline $\begin{array}{c}\text { Drucker-Prager } \\
\text { hydrostatic stress } \\
\text { coefficient }\end{array}$ & 0.375 & \\
\hline $\begin{array}{c}\text { Strain hardening } \\
\text { exponent }\end{array}$ & 50 & \\
\hline Cutoff plastic strain & $1 \times 10^{5}$ & \\
\hline Low rate exponent & 100 & \\
\hline High rate exponent & 100 & \\
\hline $\begin{array}{c}\text { Reference plastic strain } \\
\text { rate }\end{array}$ & 1 & $\mathrm{~s}^{-1}$ \\
\hline Young's modulus & $9.5 \times 10^{10}$ & $\mathrm{~Pa}$ \\
\hline Poisson's ratio & 0.315 & \\
\hline
\end{tabular}

* Corresponding author. Tel.:+1 785-532-3731

E-mail address: lei@ksu.edu 
Table 2: Thermal properties of nano-HAP

\begin{tabular}{|c|c|c|}
\hline $\begin{array}{c}\text { Workpiece } \\
\text { thermal } \\
\text { parameters }\end{array}$ & Magnitude & Unit \\
\hline $\begin{array}{c}\text { Thermal } \\
\text { conductivity }\end{array}$ & 1.2 & $\mathrm{~W} / \mathrm{m} \cdot \mathrm{K}$ \\
\hline Heat capacity & 1739 & $\mathrm{~J} / \mathrm{kg} \cdot \mathrm{K}$ \\
\hline $\begin{array}{c}\text { Coefficient of } \\
\text { thermal } \\
\text { expansion }\end{array}$ & $1.6 \times 10^{-5}$ & $\mathrm{~K}^{-1}$ \\
\hline $\begin{array}{c}\text { Cutoff } \\
\text { temperature }\end{array}$ & 1000 & ${ }^{\circ} \mathrm{C}$ \\
\hline $\begin{array}{c}\text { Melting } \\
\text { temperature }\end{array}$ & 1500 & ${ }^{\circ} \mathrm{C}$ \\
\hline
\end{tabular}

Because of the lower material hardness, ductile regime machining should theoretically be easier to achieve. The two main characteristics of ductile regime machining are that a continuous chip is formed and that the cutting pressure is greater than or equal to the workpiece material's hardness. Achieving ductile regime machining is very important when machining material intended for a bone implant because DRM can leave the material surface free of cracks, which helps to avoid a potentially disastrous weakening and/or breakage of the implanted material [11]. The approach simulated in this study to make ductile regime machining of a brittle ceramic more easily achieved is laser assisted machining. By heating the material surface with a laser, the workpiece can be thermally softened, thus reducing its hardness and increasing its machinability [6]. The degree of laser heating applied to the workpiece surface (expressed by the temperature of the thermal boundary condition applied to the top of the workpiece) are room temperature (20 $\left.{ }^{\circ} \mathrm{C}\right), 200{ }^{\circ} \mathrm{C}, 600{ }^{\circ} \mathrm{C}, 1000{ }^{\circ} \mathrm{C}$, and $1400{ }^{\circ} \mathrm{C}$ (close to the material's melting point of $1500{ }^{\circ} \mathrm{C}$ ). Table 2 shows the thermal properties of nano-HAP. 
Along with the laser heating effect, the tool rake angle and edge radius/depth of cut combination were varied (the edge radius and depth of cut are grouped together in this way because the depth of cut to edge radius ratio was kept constant at 10; therefore they varied in a directly proportional manner). Tool parameters and geometry used in this research are given below in Table 3. The material used for the tool is single crystal diamond. Tool material properties were obtained from Virkar and Patten [6].

Table 3: Tool parameters/geometry Material properties obtained from [6]

\begin{tabular}{|c|c|c|}
\hline $\begin{array}{c}\text { Tool } \\
\text { property/geometry }\end{array}$ & Magnitude & Unit \\
\hline Thermal conductivity & 1500 & $\mathrm{~W} / \mathrm{m} \cdot \mathrm{K}$ \\
\hline Heat capacity & 471.5 & $\mathrm{~J} / \mathrm{kg} \cdot \mathrm{K}$ \\
\hline Density & 3520 & $\mathrm{~kg} / \mathrm{m}^{3}$ \\
\hline $\begin{array}{c}\text { Coefficient of thermal } \\
\text { expansion }\end{array}$ & $1 \times 10^{-6}$ & $\mathrm{~K}^{-1}$ \\
\hline Young's modulus & $1.05 \times 10^{12}$ & $\mathrm{~Pa}$ \\
\hline Poisson's ratio & 0.2 & \\
\hline Rake angle & $0,-20,-45$ & degree \\
\hline Relief angle & 5 & degree \\
\hline Edge radius & $1,5,10$ & $\mu \mathrm{m}$ \\
\hline
\end{tabular}

In this research, the materials were modeled by using the Drucker-Prager Thermal Expansion constitutive model, to account for thermal expansion of the workpiece and the tool as heating occurred and to satisfy the need for a pressure-sensitive yield criterion. A pressuresensitive yield criterion is necessary because DRM is pressure dependent [12] and DRM can only be achieved when the cutting pressure along the shear plane is greater than or equal to the material hardness. For the cutting parameters, all workpiece and tool parameters were kept fixed except for the following three: a) the temperature of the thermal boundary condition applied at the top surface of the workpiece, b) the rake angle of the tool, c) the tool edge radius/depth of cut 
(kept in a constant ratio of depth of cut to edge radius $=10: 1$; therefore, can be treated as one variable as they vary proportionally and dependently). Table 4 gives the cutting conditions used.

Table 4: Cutting conditions

\begin{tabular}{|c|c|c|}
\hline Cutting condition & Magnitude(s) & Unit \\
\hline Edge radius/depth of cut & $\begin{array}{l}1 / 10,5 / 50, \\
10 / 100\end{array}$ & $\mu \mathrm{m}, \mu \mathrm{m} / \mathrm{rev}$ \\
\hline Cutting speed & 60 & $\mathrm{~m} / \mathrm{min}$ \\
\hline Width of cut & 0.01 & $\mathrm{~mm}$ \\
\hline Coefficient of friction & 0.3 & \\
\hline Initial temperature, $\mathrm{T}_{0}$ & 20 & ${ }^{\circ} \mathrm{C}$ \\
\hline
\end{tabular}

When the simulations were completed, they were graphically analyzed using the program Tecplot 360. The cutting forces and pressures were probed at steady state and recorded. To find the critical depth of cut, the pressure contour was manually changed from the default contour levels to new contour levels in which the highest contour level (red) would show all the points under a pressure greater than or equal to the hardness of the workpiece at the given temperature. An example is given below in Figure 2.

This was given under each figure as the "Critical DRM Pressure". This is a characteristic requirement of achieving ductile regime machining. To find this pressure, the hardness of the workpiece material was calculated by simply plugging the temperature into the equation:

$$
H=500-\frac{1}{3} T
$$

where $\mathrm{H}$ is the hardness in $\mathrm{MPa}, \mathrm{T}$ is the temperature in ${ }^{\circ} \mathrm{C}$, and the slope of the linear thermal softening curve is $-1 / 3$. The simulations with a $20^{\circ} \mathrm{C}$ thermal boundary condition, however, used a critical DRM pressure of $500 \mathrm{MPa}$ because the reference temperature used for all simulations is 
the standard $20^{\circ} \mathrm{C}$, or room temperature. Once the contour levels were changed appropriately to show all points at this pressure in red, a line was drawn from the tool tip to the point on the workpiece surface where the chip began to separate. This line is usually referred to as the shear plane. The greatest vertical distance within the red contour level from the tool tip to the shear plane was then measured in Tecplot 360 and recorded to obtain the resulting critical depth of cut for each simulation's given set of parameters. The shear plane and critical depth of cut are shown in Figure 2.

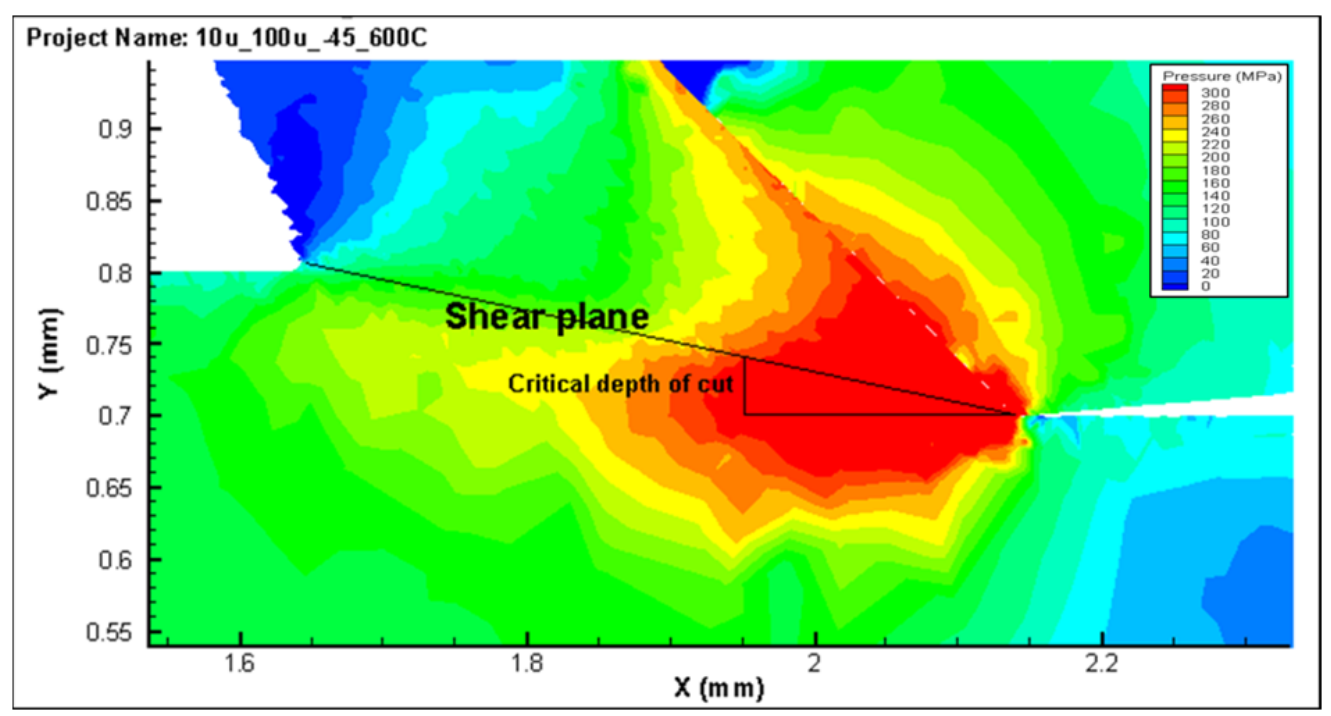

Figure 2. Sample critical depth of cut contour

\section{Constitutive Model}

As mentioned above, the Drucker-Prager constitutive model accounting for thermal expansion was used in this research. Below are explanations of the main governing equations and features that compose this model.

Drucker-Prager The Drucker-Prager yield criterion is given by the equation

$$
\sqrt{3 J_{2}}+I_{1} \alpha-\kappa=0
$$


where $I_{1}$ represents the first invariant of the stress tensor, $J_{2}$ represents the second invariant of the deviatoric stress tensor, $\alpha$ represents the Drucker-Prager hydrostatic stress coefficient, and $\kappa$ is the initial yield stress. $I_{1}$ and $J_{2}$ are given by the following equations

$$
\begin{gathered}
I_{1}=\sigma_{1}+\sigma_{2}+\sigma_{3} \\
J_{2}=\frac{1}{6}\left[\left(\sigma_{1}-\sigma_{2}\right)^{2}+\left(\sigma_{2}-\sigma_{3}\right)^{2}+\left(\sigma_{3}-\sigma_{1}\right)^{2}\right]
\end{gathered}
$$

where $\sigma_{1}, \sigma_{2}$, and $\sigma_{3}$ are principal stresses in three directions respectively [13]. The initial yield stress $\kappa$ is calculated by

$$
\kappa=\frac{2 \sigma_{c} \sigma_{t}}{\sigma_{c}+\sigma_{t}}
$$

where $\sigma_{\mathrm{c}}$ is the yield stress in compression and $\sigma_{\mathrm{t}}$ is the yield stress in tension of the material respectively. The compressive yield stress $\sigma_{\mathrm{c}}$ is set equal to the material's hardness and tensile yield stress $\sigma_{t}$ is defined as the hardness divided by 2.2 based on [14]. Using the uniaxial stress state, $I_{1}$ is simply equal to $\sigma_{1}$, and $J_{2}$ is equal to $\sigma_{1}^{2} / 3$. The hardness value of this new material is $0.5 \mathrm{GPa}$, and $\kappa$ and $\alpha$ are calculated to be $3.125 \times 10^{8} \mathrm{~Pa}$ and 0.375 , respectively.

Strain Hardening The strain hardening function is defined in AdvantEdge as:

$$
\begin{gathered}
g\left(\varepsilon^{p}\right)=\sigma_{0}\left(1+\frac{\varepsilon^{p}}{\varepsilon_{0}^{p}}\right)^{\frac{1}{n}} \quad \text { if } \quad \varepsilon^{p}<\varepsilon_{c u t}^{p} \\
g\left(\varepsilon^{p}\right)=\sigma_{0}\left(1+\frac{\varepsilon_{c u t}^{p}}{\varepsilon_{0}^{p}}\right)^{\frac{1}{n}} \quad \text { if } \quad \varepsilon^{p}>\varepsilon_{c u t}^{p}
\end{gathered}
$$

where the initial yield stress is given by $\sigma_{0}$, the plastic strain given by $\varepsilon^{\mathrm{p}}$, the reference plastic strain given by $\varepsilon_{0}^{\mathrm{p}}$, the cut off or threshold strain given by $\varepsilon_{\text {cut }}^{\mathrm{p}}$, and the strain hardening 
exponent given by $1 / \mathrm{n}[15]$. For a ceramic such as the material used in this study, a graph of the strain hardening curve should resemble Figure 3.

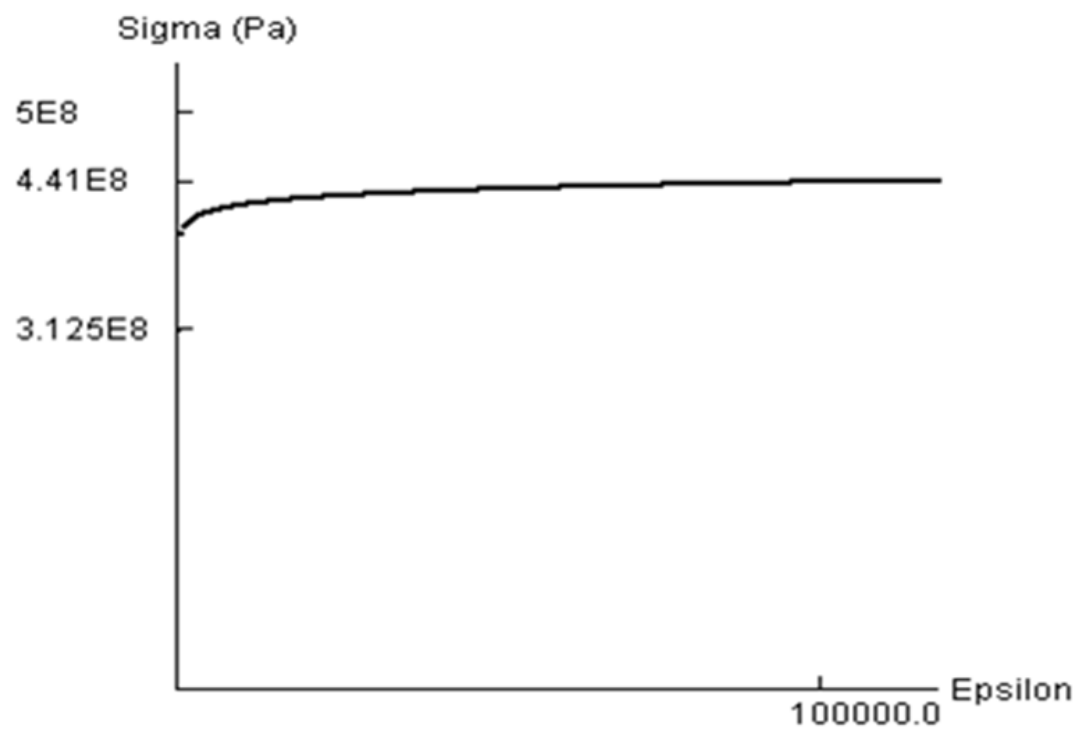

Figure 3. AdvantEdge strain hardening curve for nano-HAP[9]

Thermal Softening The thermal softening function $\mathrm{S}(\mathrm{T})$ is defined as:

$$
\begin{aligned}
& S(T)=c_{0}+c_{1} T+c_{2} T^{2}+c_{3} T^{3}+c_{4} T^{4}+c_{5} T^{5} \quad \text { if } \quad T<T_{c u t} \\
& S(T)=S\left(T_{\text {cut }}\right)+\frac{1-\left(T-T_{c u t}\right)}{T_{\text {melt }}-T_{\text {cut }}} \quad \text { if } \quad T \geq T_{\text {cut }}
\end{aligned}
$$

where $T_{\text {cut }}$ is the cut off temperature, $T$ is temperature, $T_{\text {melt }}$ is the melting point of the workpiece material, and $\mathrm{c}_{0}, \mathrm{c}_{1}, \mathrm{c}_{2}, \mathrm{c}_{3}, \mathrm{c}_{4}$, and $\mathrm{c}_{5}$ are polynomial coefficients that allow approximation by polynomial fit up to a 5 th order equation [15]. Because no experimental thermal softening data is currently available, the thermal softening function is assumed to be linear for all $\mathrm{T}$ from 
reference temperature to the melting point. In other words, the workpiece material is assumed to soften at a constant rate as temperature increases.

Thermal Expansion The thermal expansion feature for the Drucker-Prager constitutive model is accounted for using a constant coefficient of thermal expansion [15]. The coefficient of thermal expansion used for the workpiece in this study was $\alpha=1.6 \times 10^{-5} \mathrm{~K}^{-1}$.

\section{RESULTS AND DISCUSSION}

This section presents the numerical results of thermally-assisted machining of the new nanocrystalline hydroxyapatite (nano-HAP). Figure 4 shows the relationship between critical depth of cut and temperature for $-45^{\circ}$ rake angle with different edge radii. It is clear that critical depth of cut increases dramatically as the temperature increases. In Figure 4, we can also see the relationship between edge radius and critical depth of cut. As edge radius increases, critical depth of cut increases for the same temperature.

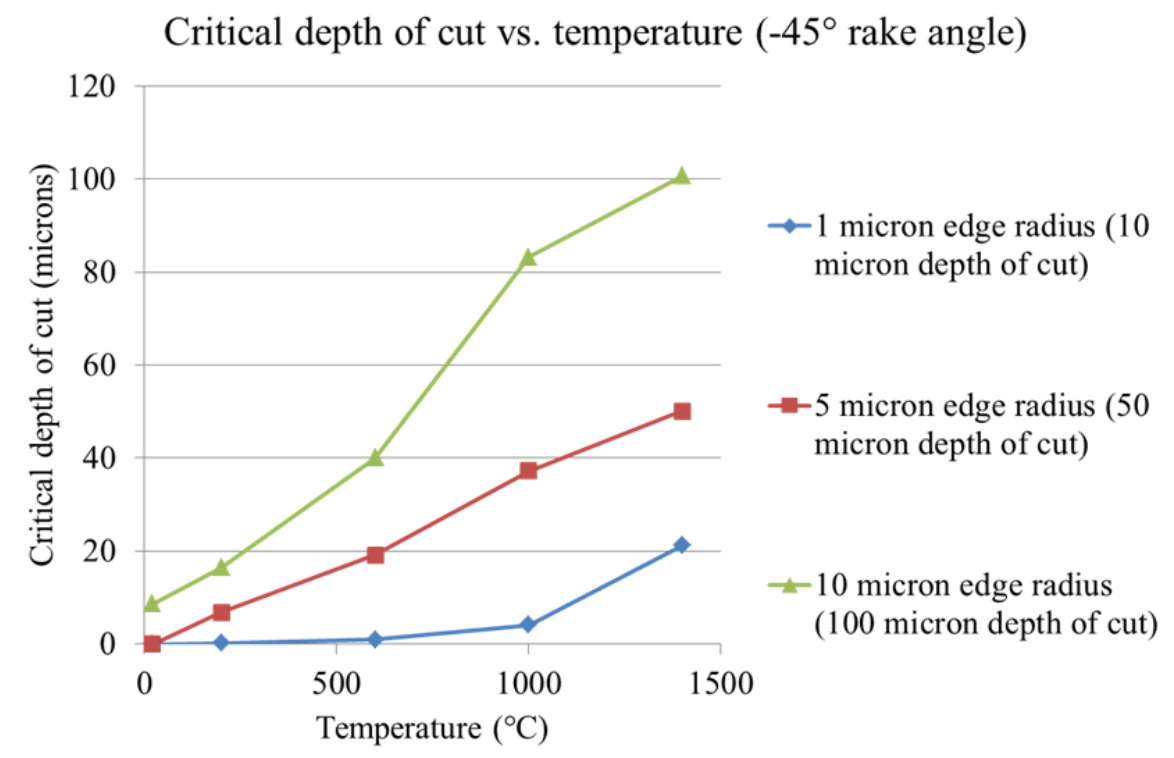

Figure 4. Critical depth of cut dependence on edge radius and temperature $\left(-45^{\circ}\right.$ rake angle)

\footnotetext{
* Corresponding author. Tel.:+1 785-532-3731

E-mail address: lei@ksu.edu
} 
Figures 5 and 6 show the relationship between critical depth of cut and workpiece temperature for $-20^{\circ}$ rake angle and $0^{\circ}$ rake angle, respectively, with different values of edge radius. From these two figures we can conclude that critical depth of cut increases dramatically as the temperature increases. However, there seems to be a threshold temperature for each condition below which the critical depth of cut is zero. This threshold temperature depends on edge radius and rake angle. Above this threshold temperature, the critical depth of cut increases with temperature at a fixed edge radius. It also increases with edge radius at a fixed temperature above the threshold value.

Critical depth of cut vs. temperature $\left(-20^{\circ}\right.$ rake angle)

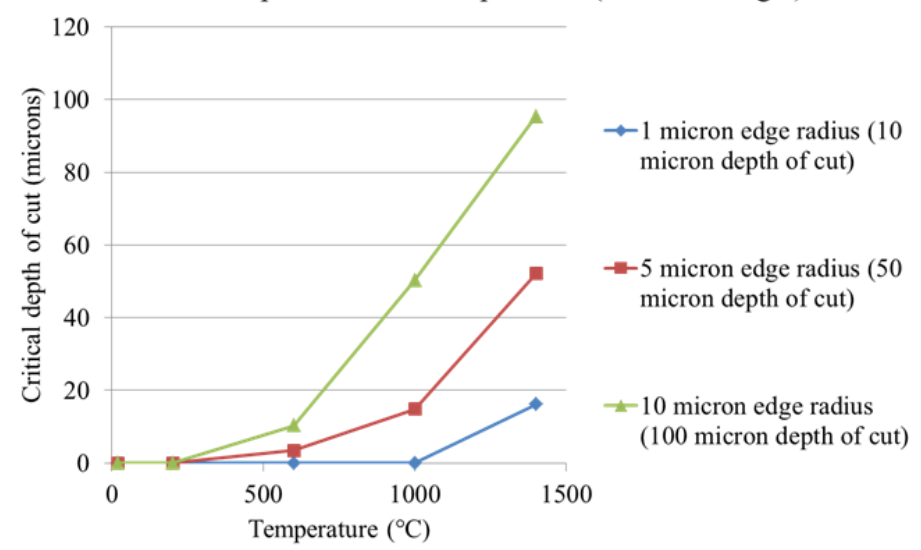

Figure 5. Critical depth of cut dependence on edge radius and temperature $\left(-20^{\circ}\right.$ rake angle $)$

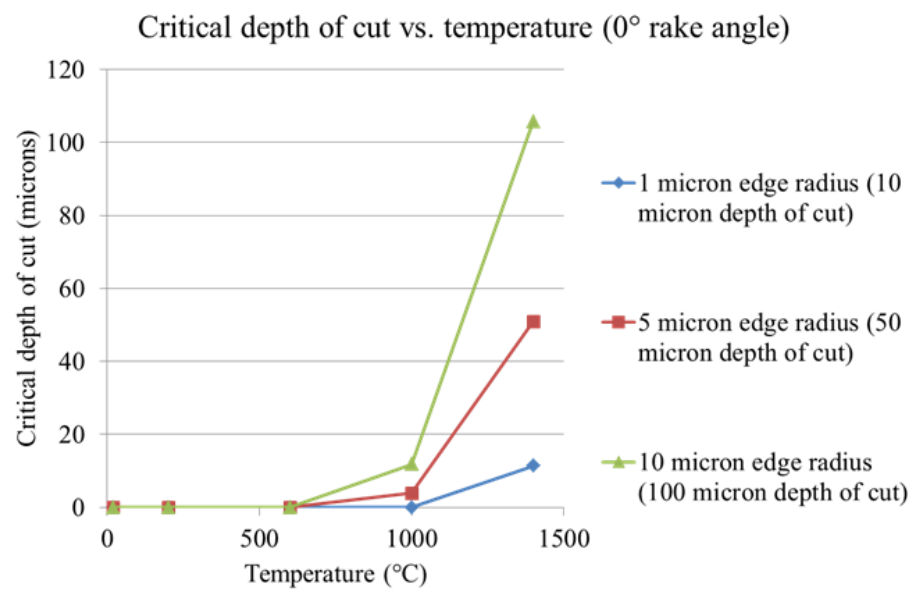

Figure 6. Critical depth of cut dependence on edge radius and temperature $\left(0^{\circ}\right.$ rake angle $)$ 
Figure 7 shows critical depth of cut dependence on temperature and rake angle for 1 micron edge radius ( 10 micron depth of cut). It is obvious that when the edge radius is 1 micron, the critical depth of cut values are equal to zero when the temperature is $20^{\circ} \mathrm{C}, 200{ }^{\circ} \mathrm{C}, 400{ }^{\circ} \mathrm{C}$, and $1000{ }^{\circ} \mathrm{C}$ for $0^{\circ}$ rake angle and $-20^{\circ}$ rake angle. Only when temperature is equal to $1400{ }^{\circ} \mathrm{C}$ can we get nonzero critical depth of cut values for these two rake angles. For $-45^{\circ}$ rake angle, we can get nonzero critical depth of cut when the temperature is equal to $200^{\circ} \mathrm{C}, 400^{\circ} \mathrm{C}, 1000^{\circ} \mathrm{C}$, and $1400^{\circ} \mathrm{C}$. In addition, for the same temperature, the critical depth of cut value for $-45^{\circ}$ rake angle is much higher than for zero and $-20^{\circ}$ rake angles. We can conclude that when the edge radius is small, by using higher negative rake angle, we can achieve ductile regime machining (DRM) at relatively low temperature.

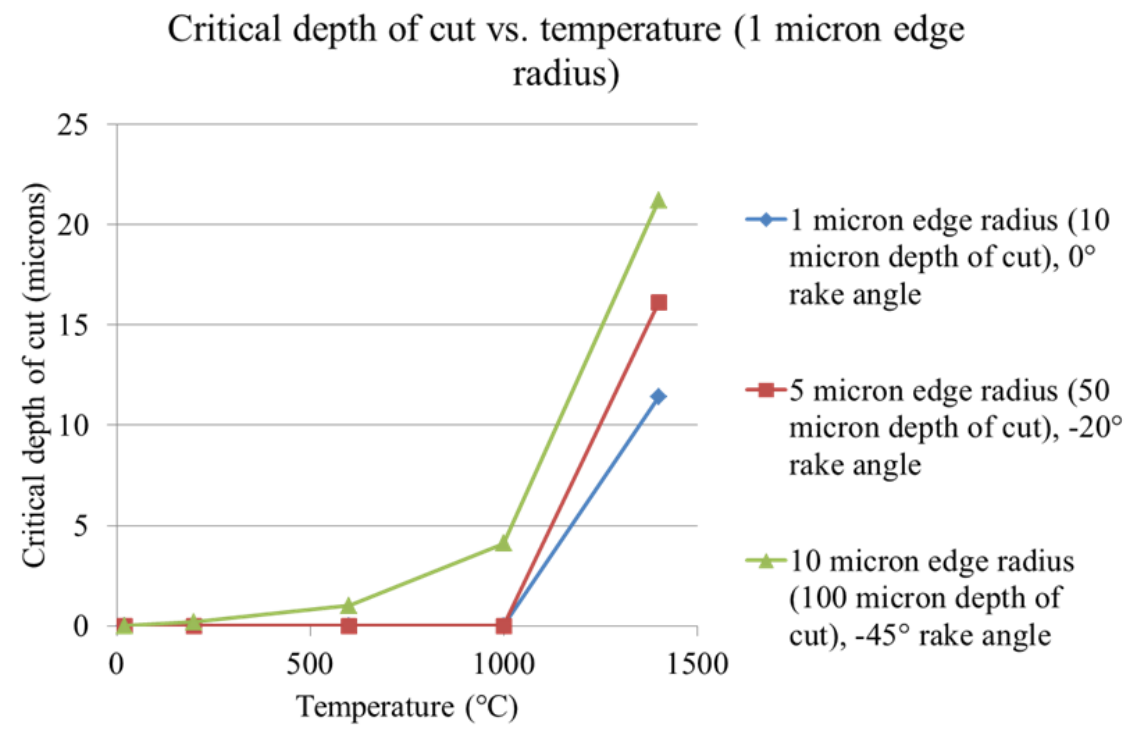

Figure 7. Critical depth of cut dependence on rake angle and temperature (1 micron edge radius, 10 micron depth of cut)

Figures 8 and 9 show the critical depth of cut dependence on rake angle and temperature for 5 and 10 micron edge radii ( 50 and 100 micron depths of cut) respectively. It is clear that

* Corresponding author. Tel.:+1 785-532-3731

E-mail address: lei@ksu.edu 
when temperature increases, the critical depth of cut increases for each of these rake angles ($45^{\circ},-20^{\circ}$, and $0^{\circ}$ ). For Figure 8 , when we compare the second green triangle corresponding to $45^{\circ}$ rake angle and $200^{\circ} \mathrm{C}$, the third red square corresponding to $-20^{\circ}$ rake angle and $600^{\circ} \mathrm{C}$, and fourth blue diamond corresponding to $0^{\circ}$ rake angle and $1000^{\circ} \mathrm{C}$, we find that if we heat the workpiece to a higher temperature, we can achieve the comparable critical depth of cut by using smaller negative rake angle tool. This conclusion is supported when we compare the third green triangle corresponding to $-45^{\circ}$ rake angle and $600^{\circ} \mathrm{C}$ and the fourth red square corresponding to $20^{\circ}$ rake angle and $1000^{\circ} \mathrm{C}$. In addition, if the workpiece is heated to $1400^{\circ} \mathrm{C}$, these three rake angles generated comparable critical depth of cut. This conclusion is validated by the data presented in Figure 9. This conclusion is very useful for the machining of thin plates since higher negative rake angle generates higher thrust force, which usually deforms the workpiece and consequently deteriorates dimensional accuracy of the finished workpiece.

Critical depth of cut vs. temperature (10 micron edge radius)

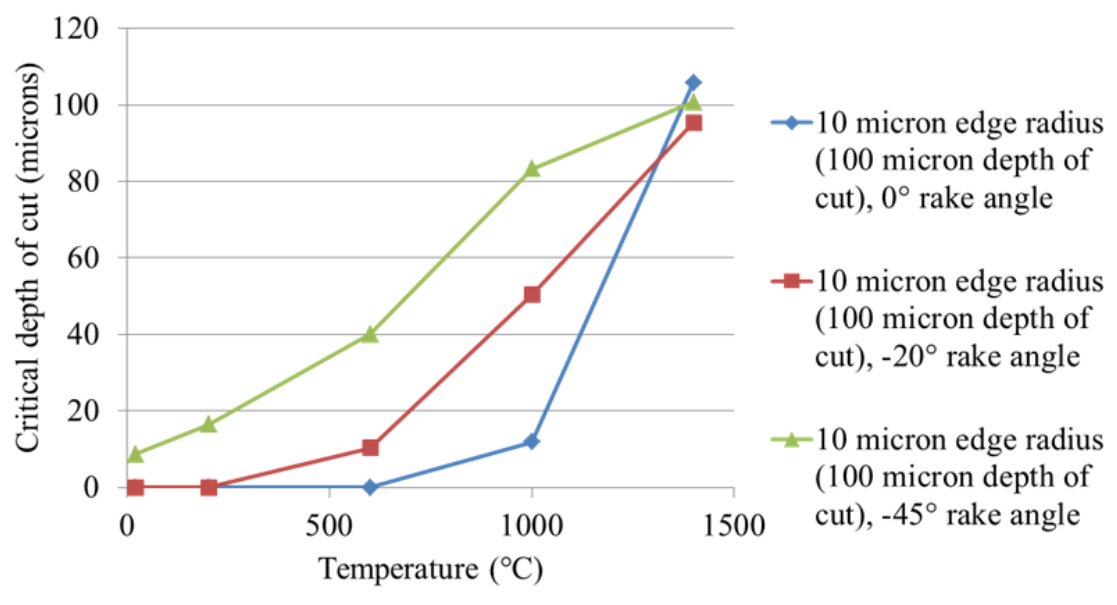

Figure 8. Critical depth of cut dependence on rake angle and temperature (5 micron edge radius, 50 micron depth of cut)

* Corresponding author. Tel.:+1 785-532-3731

E-mail address: lei@ksu.edu 
Critical depth of cut vs. temperature (10 micron edge radius)

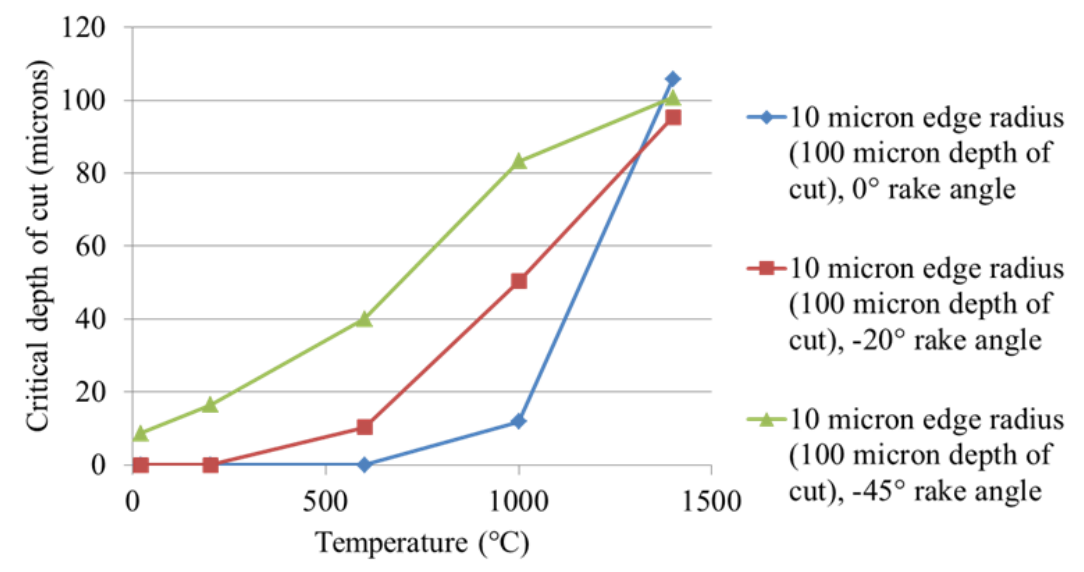

Figure 9. Critical depth of cut dependence on rake angle and temperature (10 micron edge radius, 100 micron depth of cut)

Cutting and thrust forces also showed dependence on temperature, rake angle, and edge radius. As can be seen from Figure 10 to Figure 18, cutting force decreases as temperature increases. This is expected because as temperature increases, the material becomes softer and therefore is easier to cut.

From Figure 10 to Figure 12, we can see that with a $0^{\circ}$ rake angle, the cutting force is always much larger than the thrust force. The ratio between them is about 2.6 , almost independent of temperature and edge radius. When edge radius (or depth of cut) increases, the two force components increase almost proportionally for the same temperature. 
Cutting force/thrust force ( 1 micron edge radius/10 micron depth of cut, $0^{\circ}$ rake angle)

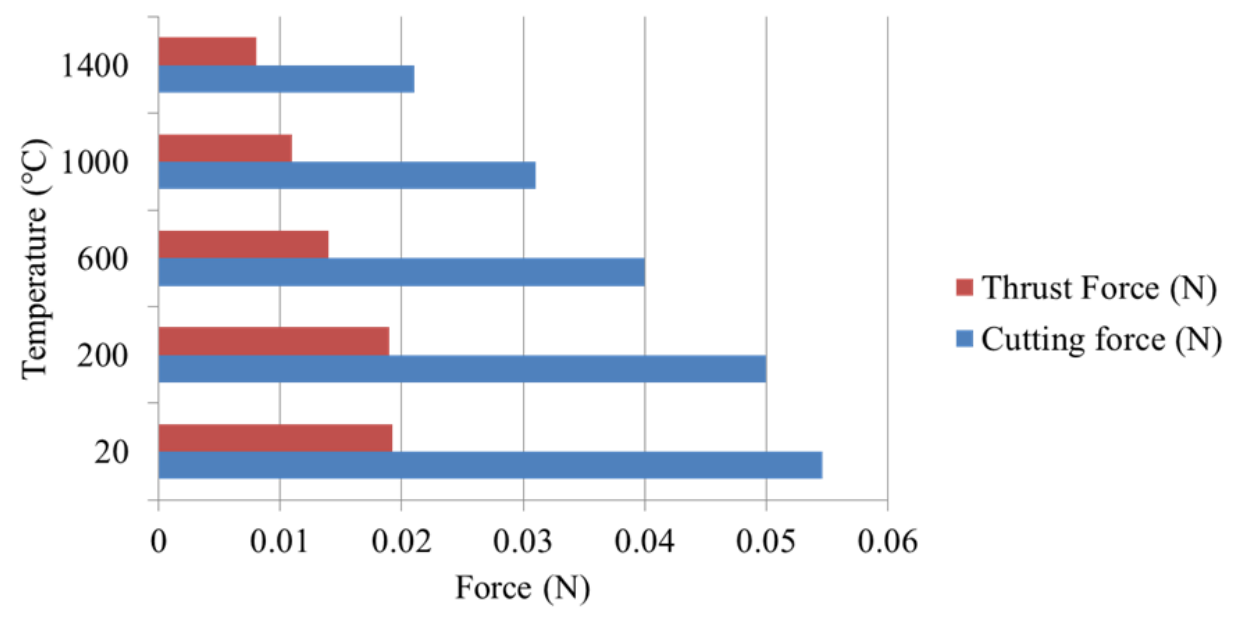

Figure 10. Cutting force/thrust force dependence on temperature (1 micron edge radius (10 micron depth of cut) and $0^{\circ}$ rake angle)

Cutting force/thrust force (5 micron edge radius/50 micron depth of cut, $0^{\circ}$ rake angle)

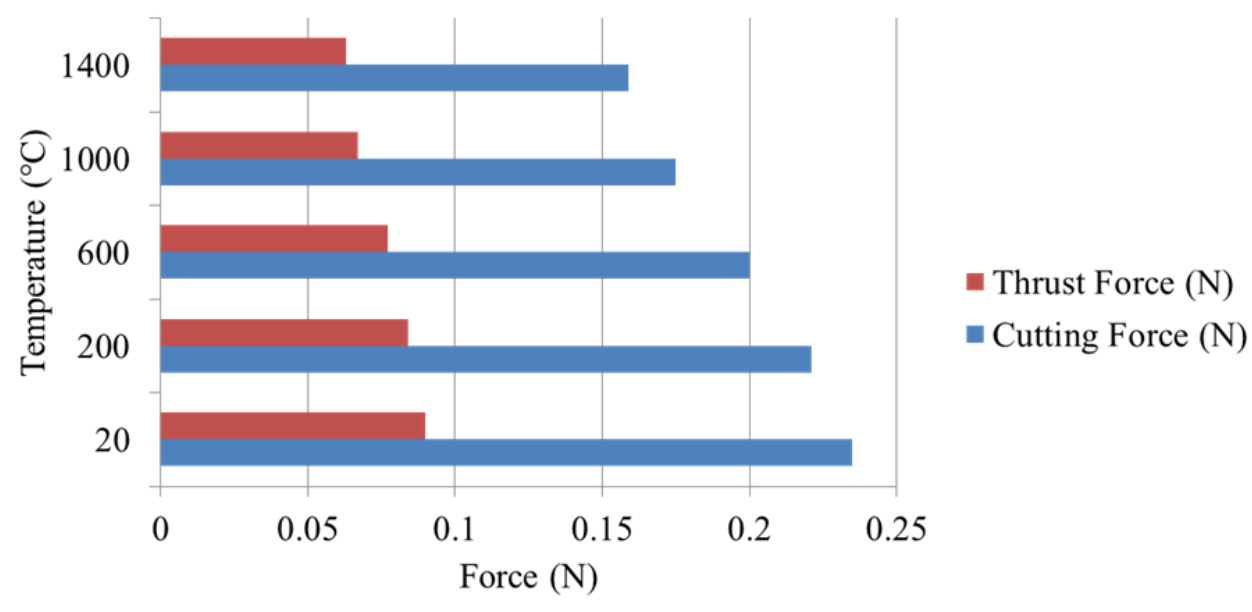

Figure 11. Cutting force/thrust force dependence on temperature (5 micron edge radius (50 micron depth of cut) and $0^{\circ}$ rake angle) 
Cutting force/thrust force $(10$ micron edge radius/100 micron depth of cut, $0^{\circ}$ rake angle)

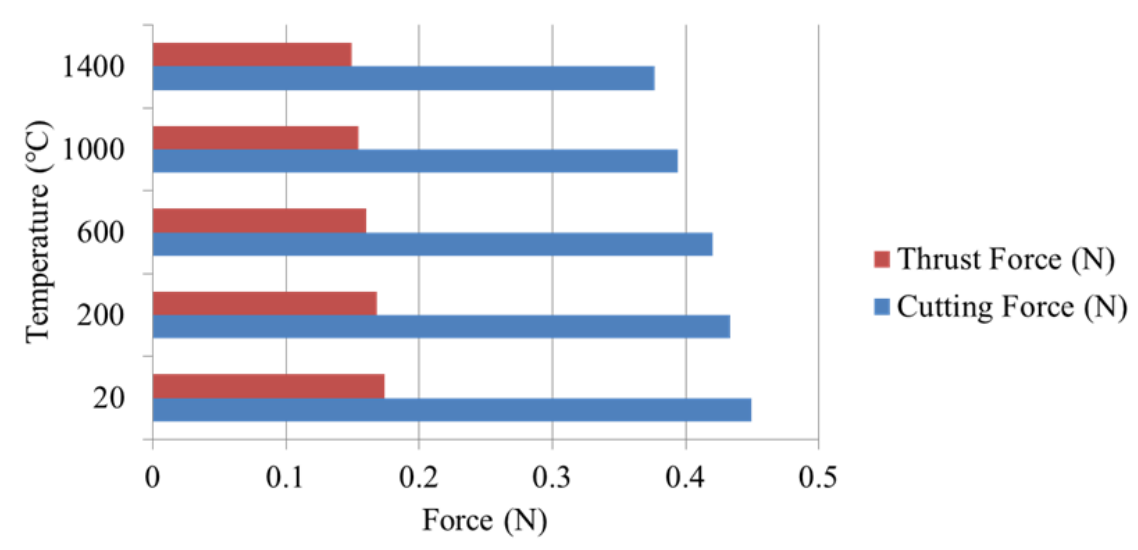

Figure 12. Cutting force/thrust force dependence on temperature (10 micron edge radius (100 micron depth of cut) and $0^{\circ}$ rake angle)

From Figure 13 to Figure 15 , we can see when rake angle is equal to $-20^{\circ}$, the cutting force is always larger than the thrust force. The ratio between them is about 1.3, almost independent of temperature and edge radius. In addition, it is clear that as the edge radius (or depth of cut) increases, both cutting force and thrust force increase for the same temperature. These two conclusions are very similar to those obtained for a $0^{\circ}$ rake angle.

Cutting force/thrust force ( 1 micron edge radius/10 micron depth of cut, $-20^{\circ}$ rake angle)

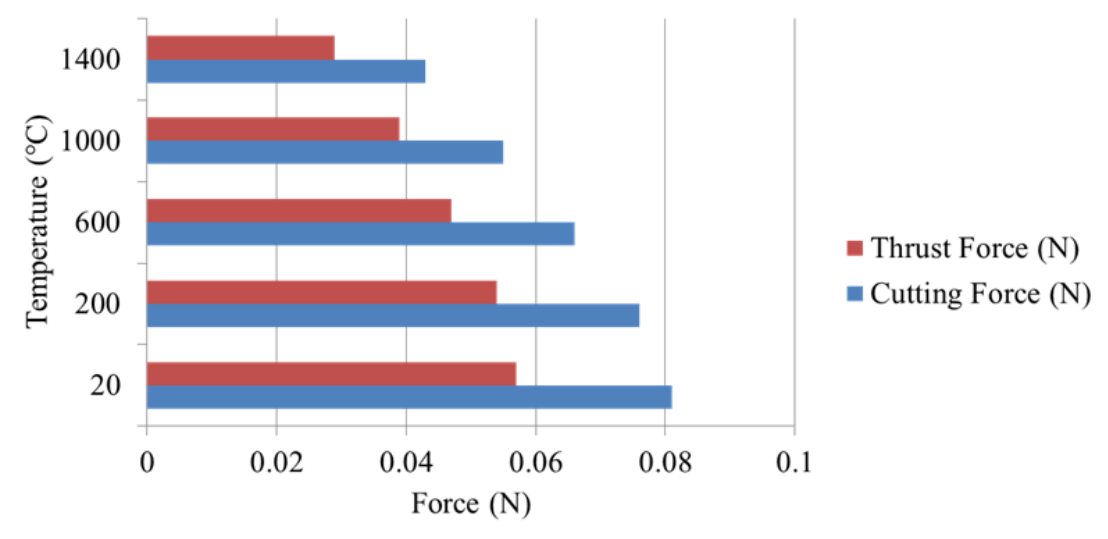

Figure 13. Cutting force/thrust force dependence on temperature (1 micron edge radius (10 micron depth of cut) and $-20^{\circ}$ rake angle) 
Cutting force /thrust force ( 5 micron edge radius $/ 50$ micron depth of cut, $-20^{\circ}$ rake angle)

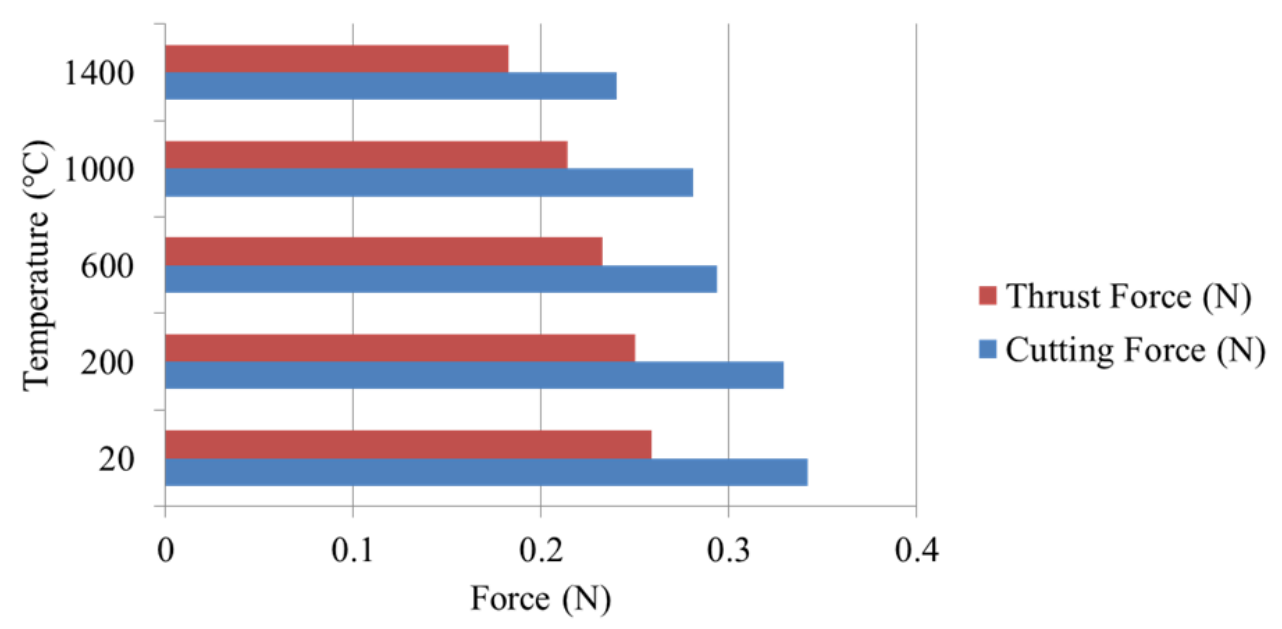

Figure 14. Cutting force/thrust force dependence on temperature (5 micron edge radius (50 micron depth of cut) and $-20^{\circ}$ rake angle)

Cutting force/thrust force (10 micron edge radius/100 micron depth of cut, $-20^{\circ}$ rake angle)

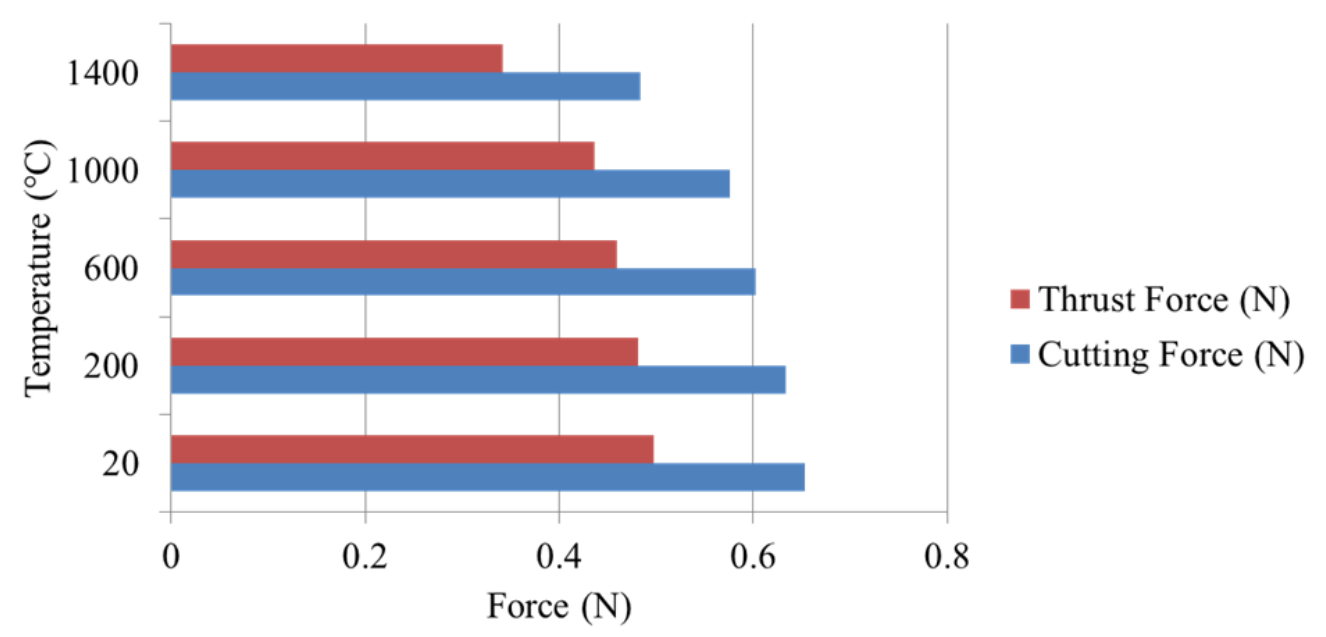

Figure 15. Cutting force/thrust force dependence on temperature (10 micron edge radius (100 micron depth of cut) and $-20^{\circ}$ rake angle) 
From Figure 16 to Figure 18 , we can see that when rake angle is equal to $-45^{\circ}$, the cutting force is always smaller than the thrust force. The ratio between them is about 0.7 , almost independent of temperature and edge radius. In addition, it is clear that as the edge radius increases, both cutting force and thrust force increase for the same temperature.

Cutting force/thrust force ( 1 micron edge radius/10 micron depth of cut, $-45^{\circ}$ rake angle)

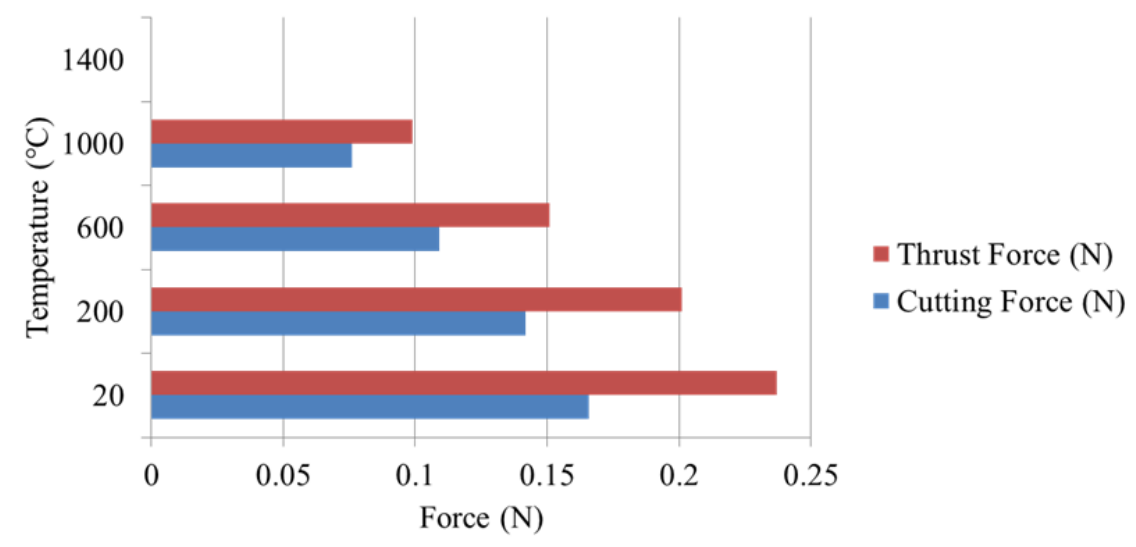

Figure 16. Cutting force/thrust force dependence on temperature (1 micron edge radius (10 micron depth of cut) and $-45^{\circ}$ rake angle)

Cutting forces/thrust forces ( 5 micron edge radius $/ 50$ micron depth of cut, $-45^{\circ}$ rake angle)

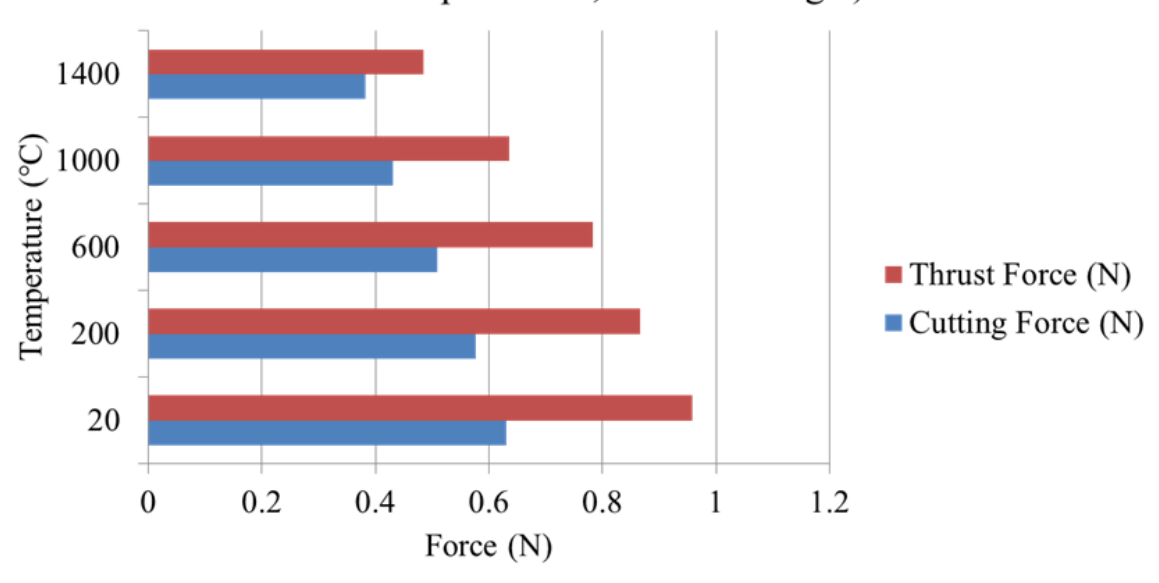

Figure 17. Cutting force/thrust force dependence on temperature (5 micron edge radius (50 micron depth of cut) and $-45^{\circ}$ rake angle) 
Cutting force/thrust force (10 micron edge radius/100

micron depth of cut, $-45^{\circ}$ rake angle)

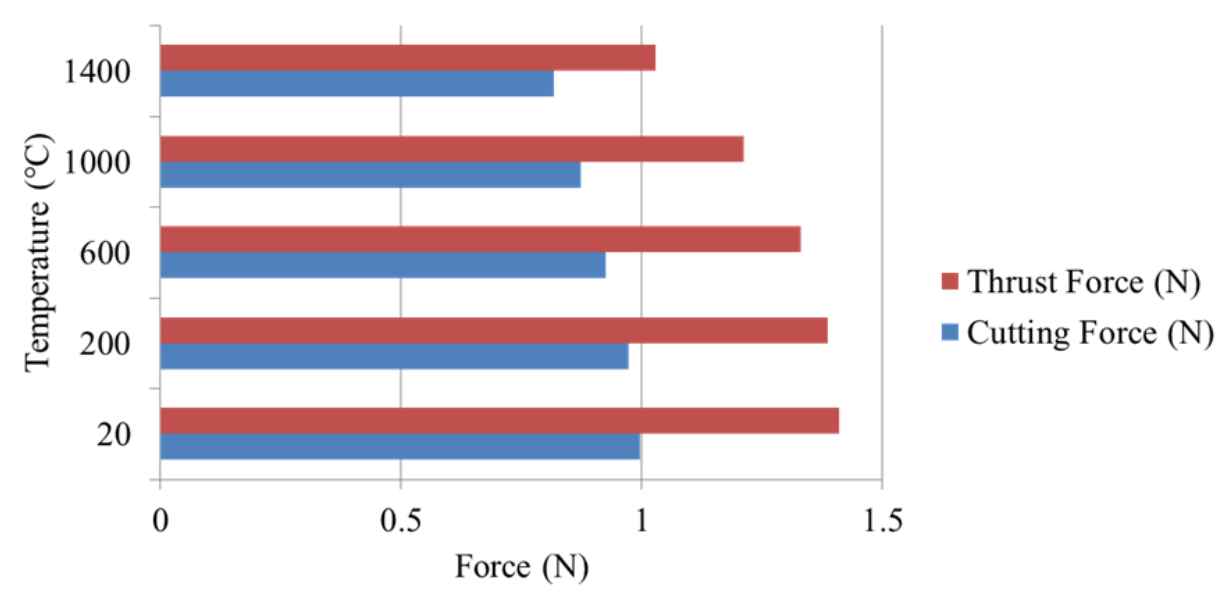

Figure 18. Cutting force/thrust force dependence on temperature (10 micron edge radius (100 micron depth of cut) and $-45^{\circ}$ rake angle)

To quantify the relationship between the critical depth of cut and the machining conditions, a quadratic model was formulated using MATLAB. Figure 19 is a MATLAB plot showing the dependence of critical depth of cut on temperature, rake angle, and edge radius that was obtained using the multiple linear regression technique. This plot clearly supports the assertion that critical depth of cut increases as temperature and edge radius increase, and also as the rake angle is made more negative. The equation obtained from the regression analysis takes the form below,

$d_{c}=10.6-5.29 \times 10^{-2} T+0.288 R-2.88 r-1.33 \times 10^{-4} T R+6.55 \times 10^{-3} T r-5.84 \times$ $10^{-2} R r+3.76 \times 10^{-5} T^{2}+4.32 \times 10^{-3} R^{2}+7.92 \times 10^{-2} r^{2}$

where $d_{c}$ is the critical depth of cut, $T$ is the cutting temperature in ${ }^{\circ} \mathrm{C}, \mathrm{R}$ is the rake angle in degrees, and $\mathrm{r}$ is the edge radius in $\mu \mathrm{m}$. This equation can be used to assist in the selection of machining conditions to achieve a desired critical depth of cut. 


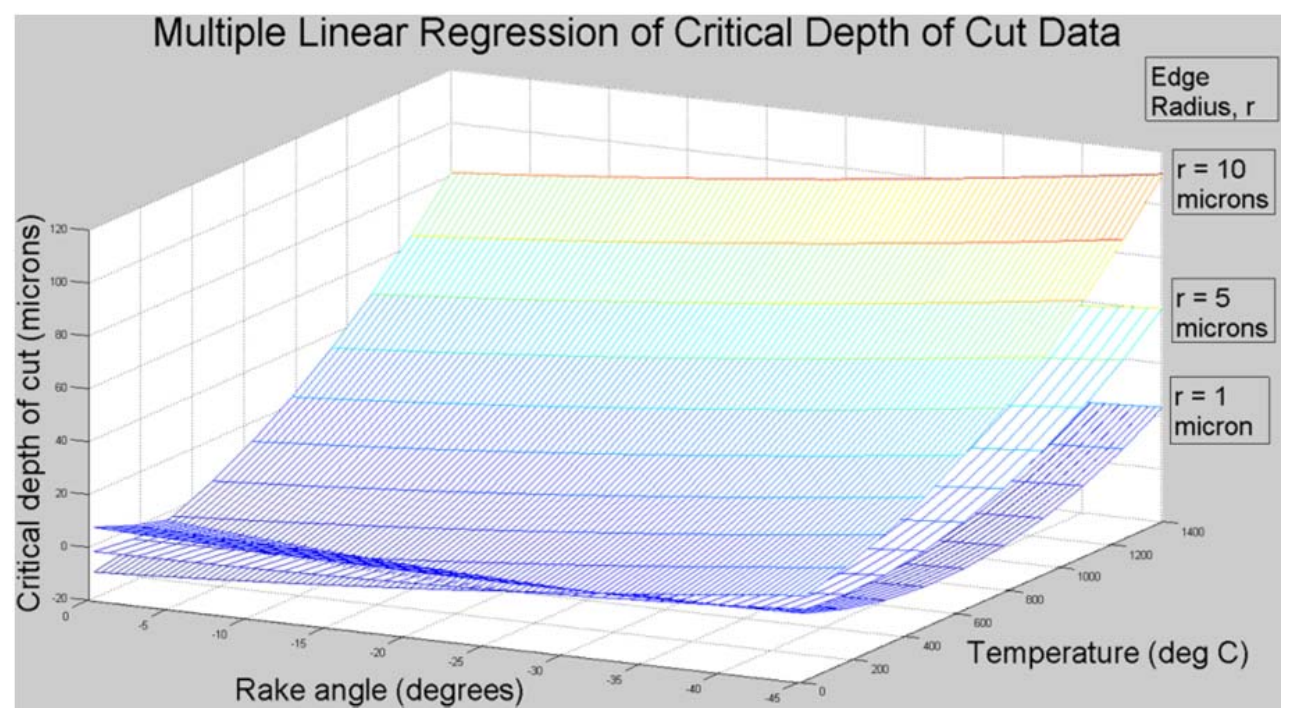

Figure 19. Multiple linear regression MATLAB plot of critical depth of cut depending on temperature, rake angle, and edge radius

\section{CONCLUSIONS}

In this paper, FEM is used to model and simulate the two dimensional (2D) laser assisted machining process of the newly developed nano-HAP to gain insights on the critical depth of cut under which ductile regime machining of this material can be achieved. The new findings are given as follows:

1) If we select cutting conditions carefully, we can achieve ductile regime machining for this newly developed nano-HAP material.

2) For different combinations of rake angle and edge radius, the critical depth of cut increases as thermal boundary temperature increases if the temperature is above the threshold temperature. 
3) For the same rake angle, a high critical depth of cut is achieved if a high edge radius is used.

This tells us that we can increase edge radius to get high critical depth of cut and at the same time to achieve high productivity.

4) If the edge radius is low, in order to achieve ductile regime machining of this brittle material, we need to apply a very high thermal boundary temperature or use a high negative rake angle.

5) If we use higher thermal boundary temperature for smaller negative or $0^{\circ}$ rake angle, we can achieve the comparable critical depth of cut we get by using a higher negative rake angle. This is very useful when we machine thin plates since higher negative rake angles usually generate higher thrust forces which deteriorate the dimensional accuracy of the finished part.

6) When $0^{\circ}$ rake angle or $-20^{\circ}$ rake angle is used, thrust force is smaller than the cutting force for different cutting conditions. On the contrary, thrust force is larger than the cutting force when a $-45^{\circ}$ rake angle is used.

\section{REFERENCES}

[1] Ahn, E.S., Gleason, N.J., Nakahira, A., Ying, J.Y., 2001, "Nanostructure processing of hydroxyapatite-based bioceramics," Nano Letters, Vol. 1, No. 3, pp. 149-153.

[2] Ying, J. Y., Ahn, E. S., Nakahira, A., 1998, "Nanocrystallineapatites and composites, prostheses incorporating them, and method for their production," United States Patent No. 6,013,591, Massachusetts Institute of Technology.

[3] Suchanek, W., Yoshimura, M., 1998, "Processing and properties of hydroxyapatite-based biomaterials for use as hard tissue replacement implants," Journal of Materials Research, Vol. 13, No. 1, pp. 94-117.

[4] Zhang, L., Zarudi, I., 2001, "Towards deeper understanding of plastic deformation in monocrystalline Silicon,” International Journal of Mechanical Sciences, Vol. 43, pp. 1985-1996.

[5] Ajjarapu, S. K., 2004, "Ductile regime machining of silicon nitride: a numerical study using Drucker-Prager material model", Transactions of NAMRI/SME, Vol. 32, pp. 519-524.

[6] Virkar S.R., Patten, J. A., 2010, "Simulation of thermal effects for the analysis of micro laser assisted machining", Transactions of ICOMM/4M, Vol. 53, pp. 319-325.

[7] Fischer, G.R., Bardhan, P., and Geiger, J.E., 1983, "The lattice thermal expansion of hydroxyapatite," Journal of Materials Science Letters, Vol. 2, No. 10, pp. 577-578.

* Corresponding author. Tel.:+1 785-532-3731

E-mail address: lei@ksu.edu 
[8] Bento, A.C., Almond, D.P., Brown, S.R., and Turner, I.G., 1996, "Thermal and optical characterization of the calcium phosphate biomaterial hydroxyapatite," Journal of Applied Physics, Vol. 79, No. 9, pp. 6848-52.

[9] Norton, J., Malik, K.R., Darr, J.A., and Rehman, I., 2006, "Recent development in processing and surface modification of hydroxyapatite," Advances in Applied Ceramics, Vol. 105, No. 3, pp. 113-139.

[10] Rodríguez, B., Romero, A., Soto, O., and de Varorna, O., 2007, "Biomaterials for Orthopaedics," academic.uprm.edu/ mgoyal/materialsmay2004/k04orthopaedicppt.pdf.

[11] Neo, W.K., Kumar, A.S., Rahman, M., 2012, "A Review On the Current Research Trends in Ductile Regime Machining", International Journal of Advance Manufacturing Technology, pp. 1-16

[12] Virkar, S.R., 2010, "Numerical Simulations and Analysis of Ductile Mode Micro Laser Assisted Machining of Silicon Carbide", Western Michigan University, Kalamazoo, MI.

[13] Ajjarapu, S.K., Patten, J.A., Cherukuri, H., Brand, C., 2004, "Numerical Simulations of Ductile Regime Machining of Silicon Nitride Using the Drucker-Prager Material Model", Proceedings of the Institution of Mechanical Engineers, 218(6), pp. 577-582

[14] Gilman, J.J., 1975, "Relationship Between Impact Yield Stress and Indentation Hardness", Journal of Applied Physics, 46 (4), pp. 1435-1436.

[15] AdvantEdge FEM User's Manual, Version 5.9, 2012 